\title{
Soil Is Still an Unknown Biological System
}

\author{
Paolo Nannipieri 1 \\ Department of Agriculture, Food, Environment and Forestry, University of Florence, 50121 Florence, Italy; \\ paolo.nannipieri@unifi.it
}

Received: 24 April 2020; Accepted: 26 May 2020; Published: 27 May 2020

\begin{abstract}
More than a thousand million cells encompassing bacteria, fungi, archaea, and protists inhabit a handful of soil. The bacterial and fungal biomass can account for 1-2 and 2-5 tha ${ }^{-1}$ in temperate grassland soils, respectively. Despite this huge microbial biomass, the volume occupied by microorganisms is less than $1 \%$ of the available soil volume because most micro-niches are hostile environments. Soil microorganisms and fauna play a crucial role in soil ecosystem services, and functional redundancy is a peculiar characteristic of soil as a biological system. Complex interactions are often mediated by molecular signals that occur between microbes, microbes and plants, and microbes and animals. Several microbial species have been detected in soil using molecular techniques, particularly amplicon sequencing and metagenomics. However, their activities in situ are still poorly known because the use of soil metatranscriptomics and, in particular, soil proteomics is still a technical challenge. A holistic approach with the use of labelled compounds can give quantitative information on nutrient dynamics in the soil-plant system. Despite the remarkable technical progresses and the use of imaginative approaches, there are many knowledge gaps about soil as a biological system. These gaps are discussed from a historic perspective, starting from the seven grand questions proposed by Selman A. Waksman in 1927.
\end{abstract}

Keywords: microbial interactions; rhizosphere; DNA; proteins; microbial diversity; microbial activity

\section{Introduction}

It is well established that soil is one of the most important natural resources, with essential functions in terrestrial ecosystems. Indeed, it supports plant growth and a myriad of living organisms; controls the fate of water in the hydrological system; and recycles the wastes and bodies of plants, animals, and microorganisms. These functions depend on the biological, chemical, and physical properties of soil. However, biological properties are more sensitive than chemical and physical properties to changes in environmental conditions, including pollution problems. This has resulted in an extensive bibliography, as shown by the several international journals and books completely dedicated to soil biological properties. However, the historic perspective is often ignored because older works, especially those created before the arrival of electric searches, are ignored. The historic perspective is important in order to have a view of the development of knowledge and thus knowledge gaps and also to promote innovative studies. Several knowledge gaps about soil as a biological system were already clear at the beginning of 1900s. In 1927, Selman Waksman proposed the following seven grand questions, which were reviewed by Mc Laren in 1977 [1] and Van Elsas and Nannipieri in 2019 [2]:

1. What organisms are active under field conditions and in what ways?

2. What associative and antagonistic influences exist among soil microflora and fauna?

3. What relationships exist between soil organic matter (SOM) transformations and soil fertility?

4. What is the meaning and significance of energy balance in soil, in particular with reference to $\mathrm{C}$ and $\mathrm{N}$ ? 
5. How do cultivated plants influence soil transformations?

6. How can one modify soil populations and to what ends?

7. What interrelationships exist between physicochemical conditions in soil and microbial activities?

The aim of this mini review is to discuss the advances in knowledge relative to these seven questions by discussing the main properties of soil as a biological system. I shall not refer to each question in this section of the mini review, because it can be easily done by the reader. On the contrary in the Perspective section, I shall discuss one knowledge gap still existing per each of the seven grand questions, evidencing that we have a lot still to learn about soil as a biological system. Of course, it is not possible to have an exhaustive review due to the complexity and vastness of the treated matter, which exceeds the limits of a single mini review. I apologize for the many reviews not cited, but this is a mini review dealing with a vast topic and the relative and extensive bibliography cannot be cited. In addition, I apologize for the brief discussion of the several topics of this review. For a more detailed discussion of the treated matter, I suggest that the reader consult the many cited reviews.

\section{Properties of Soil as a Biological System}

\subsection{Physicals Structure and Distribution of Organisms in Soil}

Soil is a peculiar environment for living organisms, being composed of solid, liquid, and gaseous phases. The solid phase prevails, and the extent of the liquid and gaseous phases can change depending on agricultural practices and climatic conditions. The soil structure-that is, the organization and arrangements of soil particles-influences the biological, chemical, and physical properties of soil. Soil particles differ in their size, shape, and chemical composition, and thus they can be linked with different bonds. Soil structure is a hierarchical organization because primary particles bind together to form secondary particles that can interact to form bigger particles, such as microaggregates and macroaggregates [3]. This process varies in time and space [4], and the organization of the solid particles creates differently sized pores that may be filled by water or telluric atmosphere. According to Elliott and Coleman [5], pores can explain the spatial separation of soil organisms because (i) microarthropods can only inhabit macropores; (ii) nematodes can also live in intermacroaggregate pores; (iii) protozoa, small nematodes, and fungi can also be present in intramacroaggregate or intremicroaggregate pores; and (iv) intramicroaggregate pores can only be occupied by bacteria and viruses [6]. Indeed, the pore occupancy depends on the organism size; for example, bacterial size is a few micrometres, that of fungi is less than $100 \mu \mathrm{m}$, and that of Acari and Collembola ranges from $100 \mu \mathrm{m}$ to $2 \mathrm{~mm}$ [6]. Such separation can have important effects on soil organisms because, for example, bacteria inhabiting intramicroaggregate pores escape protozoa predation.

Soil organisms inhabit less than $1 \%$ of the available space. The microsites (hotspots) with the higher microbial abundances are those where nutrients are available, such as the rhizosphere (the soil attached to roots), the detritusphere (the soil around a plant residue), the drilosphere (soil around biopores created by earthworms), etc. [7,8]. A plausible explanation of the limited occupancy of soil volume by living organisms is the hostile environment of most soil micro-niches; conditions such as acidity; low water or $\mathrm{O}_{2}$ availability; competition between different organisms; predation; and frequent disturbances, such as drying-rewetting and freezing-thawing cycles and the presence of toxic compounds, can inhibit the activity of soil organisms [9]. However, as shown in Table 1, the microbial biomass is huge, ranging from $1 \%$ to $5 \%$ of the organic matter of soil; these values, expressed as microbial biomass C or microbial biomass $\mathrm{N}$, can range from 280 to $1940 \mathrm{~kg} \cdot \mathrm{ha}^{-1}$ and from 40 to $385 \mathrm{~kg} \cdot \mathrm{ha}^{-1}$, respectively [10]. 
Table 1. Some values of microbial biomass C (MBC) and microbial biomass N (MBN) in soil (redrawn from Smith and Paul 1990, [10]).

\begin{tabular}{|c|c|c|c|}
\hline Soil & Vegetation & MBC (kg.ha-1) & MBN (kg.ha-1) \\
\hline Sandy loam & Pasture & 280 & 40 \\
\hline Silt loam & Cereal-grass & 288 & 48 \\
\hline Clay & Pasture & 750 & 100 \\
\hline Silt & Pasture & 800 & 309 \\
\hline Clay loam & Cereals & 1200 & 240 \\
\hline Clay loam & Wheat & 1940 & 385 \\
\hline
\end{tabular}

\subsection{Microbial Diversity and Microbial Functions}

The microbial diversity is huge, as shown by the use of molecular techniques. According to Dini-Andreote and Van Elsas [9], "A handful of soil contains, on average, more than a thousand million cells encompassing bacteria, archaea, fungi and protists-collectively called the soil microbiome". However, molecular studies have revealed that a well-defined core set of taxa is present in soils sampled from different parts of the world [9]. Two percent of bacterial phylotypes were dominant and averaged $41 \%$ of the $16 \mathrm{~S}$ rRNA gene sequences of surface soils from 237 locations across 18 countries of 6 continents [11]. Some of the ubiquitous and dominant phylotypes included Alphaproteobacteria (Bradyrhizobium spp., Sphingomonas sp., Rhodoplanes sp., Devosia sp., and Kaistobacter sp.), Betaproteobacteria (Methylibium sp. and Ramlibacte), Actinobacteria (Streptomyce ssp., Salinbacterium sp. and Mycobacterium sp.), Acidobacteria (Candidatus sp., and Salibacter), and Plancttomycetes. Less than $18 \%$ of the identified phylotypes matched an available genome at the $97 \% 16 \mathrm{~S}$ rRNA sequence similarity level, and only $40 \%$ matched even at the $90 \% 16 \mathrm{~S}$ rRNA sequence similarity level. However, the detection of a taxon does not mean it is active in soil [12]. Indeed, at least $95 \%$ of the total microbial biomass is inactive in soil, and microbial activity changes in time and space [13]. Additionally, the assumption that soil functions are those carried out by the dominant taxon under in vitro conditions may not be valid because rare taxa often play an important role in the measured microbial activity, as revealed for the alkaline phosphomonoesterase activity of soil [14] and the microbial activities of soil from a glacial retreat [15]. In addition to soil microorganisms, protozoa, nematodes, microarthropods, macroarthropods, Enchytraeidae, and Earthworms, collectively termed soil fauna, can inhabit soil [5,7]. Among the soil fauna, earthworms are the most studied and act as ecosystem engineers, with significant effects on the structure and functions of soil [16]. Viruses are also present in soil, but they have been less studied than soil organisms; they are mainly bacteriophages and can infect pathogenic bacteria as well as beneficial bacteria for plants, such as rhizobia [17]. Both the abundance and diversity of viruses are markedly affected by agricultural practices [18], and the ratio between viral and bacterial abundances is higher in soil (330-470) than in water ecosystems (1-50), but the role of viruses in biological processes and the survival of organisms in soil is poorly known [17].

Among soil organisms, bacteria and fungi play the most important role in soil processes, such as the oxidation of organic matter, including xenobiotics, $\mathrm{N}, \mathrm{P}, \mathrm{S}$, and micronutrient transformations, and have both beneficial and negative effects on plants. [8,9]. Functional redundancy characterizes several soil metabolic processes being carried out by many different microbial species; for example, the loss of microbial diversity was thought not affect processes such as $\mathrm{C}$ and $\mathrm{N}$ mineralization [8], with a certain threshold value of microbial diversity being important [19]. However, a meta-analysis showed that the loss of diversity reduced soil C respiration by $25 \%$ [20]. It is important to underline that meta-analysis concerns different soils, plant covers, agricultural practices, and climatic conditions, whereas the comparison of the response of different microbial diversities obtained in the same soil studied under laboratory conditions avoids effects due to different parameters. However, Bao et al. [21] found that the taxonomical variability was much higher than the functional variability in bacterial 
communities degrading straws. Generally, processes carried out by only some microbial species, such as nitrification, are affected by a decrease in microbial diversity [8]. Microbial diversity reduced by heavy metal pollution did not affect soil organic mineralization but affected simazine degradation [22]. It is important to underline that processes such as the mineralization of specific organic compounds in soil can only be determined by using the labelled compound with the determination of the labelled carbon dioxide, because it discriminates the behavior of added $\mathrm{C}$ from that of soil organic $\mathrm{C}$. However, by carbon dioxide there have been no insights into the sequence and type of enzymes responsible for the degradation of the organic C compound; this sequence can be different, as it occurs for the degradation of cellulose and hemicellulose [9]. Future research should study the effects of changes in microbial diversity not only on the rate of the produced carbon dioxide but also on the activities of the several enzymes which are responsible of the oxidation of the labelled compound in soil.

\subsection{The Role of Important Biological Molecules Adsorbed or Entrapped in Soil}

Another peculiar aspect of soil as a biological system is the ability of surface-reactive particles to adsorb important biological molecules, such as nucleic acids and proteins, and protect them from the degradation of the heterotrophic soil microbiome [8]. Enzymes released from active cells to degrade polymers to monomers or released after the death of microbial cells can be adsorbed and protected against proteolysis, remaining active $[23,24]$. This extracellular and stabilized enzyme activity is independent of the extant microbial activity, and it can be active under hostile conditions for microbial activity. The present enzyme assays do not distinguish the activity associated with these extracellular and stabilized enzymes from that due to microbial activity, which is due to free extracellular enzymes, enzymes attached to the outer surface of viable cells with the active site extended into the extracellular environment, and intracellular enzymes [23,24].

DNA can be released into extracellular soil environments by the lysis of dead cells [25] by the border cells of the root tip [26] and during the formation of bacterial biofilms, whose presence in soils (except for waterlogged soils) has not yet been proven [25]. DNA can move through the soil with water either by leaching or capillarity if it is not adsorbed by surface-reactive particles or degraded and used as a C, N, and P source by the heterotrophic microbial communities [25]. Adsorbed DNA can be protected against degradation by nucleases and taken up by competent bacterial cells, giving the bacterial transformation that is the incorporation of the relative gens in the genome of the host bacterial cell [25]. Despite the fact that bacterial transformation can occur at very low frequencies, it can have important implications in the gene transfer between cells located in different soil microhabitats.

\subsection{Interactions between Microbes, between Microbes and Plants, and between Microbes and Fauna}

Interactions can be categorized not only by the interacting species (bacteria, fungi, plant, animal or virus) but also by how cells sense neighboring other cells of the same species. This can occur at (i) the physical level, because two cells occupy the same microenvironment; (ii) the biochemical level, because a cell responds to molecular signals released from the other one; and (iii) the nutritional level, due to metabolic interactions between the two cells [27]. Of course, these three types of interactions can occur simultaneously [27]. Interactions between microbes have been extensively studied in vitro but not in soil due to the complexity and heterogeneity of soil. However, it is plausible to hypothesize that these interactions are very important in soil habitable microsites, which are isolated each from the other in dry but not in wet periods, when water connections are established between two separate microenvironments [8]. Of course, mobile organisms (such as protozoans; nematodes and earthworms), fungi, with their hyphae, chain-forming organisms, (such as Bacillus mycoide, actinomycetes, and fungi), and plant roots, can visit different soil microenvironments [27]. Likely, in wet periods, there is the risk of increasing anaerobic microsites due to low oxygen diffusion in water [8].

One of the most studied molecular signals between bacterial cells is the quorum sensing (QS), discovered in 1980s; it involves the regulation of several bacterial processes, such as symbiosis, virulence, competence for transformation, conjugation, antibiotic production, motility, sporulation, 
and biofilm formation [25]. These signals are important in the assemblage of bacterial cells, because the cells of species with specific QS signals can exclude the cells of species with anti-QS signaling traits [25]. There are also interactions not mediated by QS, like the release of antibiotics, which can either kill or inhibit the growth of the microbial partner. Bacteria can interact with fungi both positively and negatively; fungi can promote the soil colonization of bacteria inhabiting the external surface of their hyphae and using fungal exudates. Other positive interactions involve the bacterial use of monomers or oligomers produced by the extracellular breakdown of polymers, such as the cellulose of plant residues, due to the activity of extracellular enzymes released from fungi [25]. Negative interactions can also involve several mechanisms, such as the predatory action of myxobacteria on fungi, the release of antifungal compounds by bacteria, and the use of bacterial cells as nutrient sources by some fungal species [25]. These are only few examples of the several interactions occurring among microbial species in soil.

Of course, both fungi and bacteria can be used as nutrient sources by soil eukaryotic organisms, thus originating the soil food web. The microbial loop is an example of the complex interactions among bacteria, protists, and plants in nutrient dynamics [28]. Bacteria inhabiting the rhizosphere can grow due to the presence of the root exudates released from root tips; however, bacteria have to mine $\mathrm{N}$ from soil organic matter because root exudates are generally C-rich compounds [28]. Then, protozoa graze on bacteria, reducing their number and releasing ammonium- $\mathrm{N}$ because the $\mathrm{C} / \mathrm{N}$ ratio of protozoa cells is higher than that of bacterial cells. The released ammonium is taken up by the plant, and thus the microbial loop shifts the competition for $\mathrm{N}$ between plants and bacteria in favor of plants [28]. This is just an example of the interactions between bacteria and protists, but other issues may be involved, such as selective grazing by predators [29].

The rhizosphere is the soil around the roots with a higher microbial activity than the bulk soil as the result of rhizodepostion, which includes root exudates, mucilage, root debris, and whole detached root cells [30]. Beneficial, pathogen, and neutral microorganisms inhabit the rhizosphere soil. Among the beneficial microorganisms, the plant growth-promoting bacteria can stimulate plant growth by providing nutrients and protecting plants from various abiotic and biotic stresses (among the latter, the biological control of pathogens) [30]. Some of microorganisms can positively infect plant roots, giving origin to symbiosis after a complex molecular cross-talk involving both the release of root exudates and microbial exudates. The most studied molecular cross-talks are those between rhizobia and legumes [31] and mycorrhizae and plants [32].

Generally, microbial diversity decreases when passing from the bulk to the rhizosphere soil as the result of rhizodeposition [30]. However, soil plays a fundamental role in affecting the microbial diversity of the rhizosphere. Indeed, denaturing gradient gel electrophoresis (DGGE) profiles showed that the microbial diversity of the rhizosphere soil of Carex arenaria, a non-mycorrhizal plant species so as to avoid confounding the effects of mycorrhizae, depended on the soil type [33]. The use of sequencing confirmed that soil could impose a larger selective pressure on plant-associated bacterial communities than plant species $[34,35]$. However, the soil effect decreases by comparing microbial diversity of rhizosphere soil with that of the endosphere (the interior of roots colonized by endophytes) [36]; indeed, $40 \%$ of the variation in microbial diversity depended on the host species in the endosphere but only $17 \%$ in the rhizosphere soil when 30 angiosperms were grown in a garden soil [37].

\subsection{The Main Research Approaches}

Soil biologists and soil biochemists have struggled and still struggle with knowing what is in soil and what it is doing, with the aim not only to better know the system but also to properly quantify soil functions [9]. They have carried out different research approaches. Studies using simplified systems, such as those only using two soil components, have brought a better understanding of interactions between soil components, such as the interactions of a single clay mineral with DNA, proteins, or microbial species [23-25,38]. Of course, caution is required to extrapolate the results of these studies on simplified systems to soil, which contains a huge variety of microbial species and, for example, not 
pure clay minerals, being covered by other inorganic constituents and organic material. Even DNA and proteins are released in soil with other cellular components, which may interfere with their adsorption by surface-reactive particles. This brief discussion about the drawbacks of soil omics methods and the problems with interpreting relative data does not want to discourage their use but to help with the proper discussion of the obtained data. Nowadays, omics techniques are among the most powerful ones to determine microbial diversity and microbial functions in soil.

Knowledge of the microbial taxa inhabiting soil is improved using molecular techniques, in particular amplicon sequencing and metagenome techniques. However, these studies are often based on the assumption that the detected microbial species carry out in soil the same functions observed in vitro [12]. The presence of functional genes is often taken as a sign that the relative function potentially occurs in the soil where these genes are detected without determining the gene expression or relating this presence to the measurement of the target activity [12]. Most of the microbial species inhabiting soil are generally in a dormant state, as already mentioned [13]. In addition, rare species can be active and responsible for the target activity when the expression of genes is related to the measured activity, as reported for rare species encoding alkaline phosphomonoesterase activity [14]. It is well established that metagenome studies should be combined with proteomic analyses to gain insight into soil functions because proteins are the final expression of each genome. Unfortunately, soil proteomics still has challenges and pitfalls, such as the fact that it is not technically possible to determine all expressed proteins in soil due to their huge number, and that the complete protein extraction from soil is not possible with a single extraction procedure because proteins have different properties (low and high molecular weights, hydrophilic and hydrophobic moieties, different isoelectric points) and thus different interactions with the surface-reactive particles of soil [39].

The holistic consideration of the soil system represents the best approach to quantify nutrient transformations in the soil-plant system, especially if it is combined with the use of labelled (for example, with ${ }^{14} \mathrm{C}$ or enriched with ${ }^{15} \mathrm{~N}$ ) compounds or the determination of changes in the abundances of stable isotopes (for example, ${ }^{13} \mathrm{C}$ ) [8]. According to the holistic approach, the system is portioned into pools (for example, microbial biomass $\mathrm{C}$, microbial biomass $\mathrm{N}$ ) with a functional meaning, and fluxes between these pools can represent abiotic processes (for example, nitrate leaching or ammonia volatilization) or biotic transformations (for example, nitrification, mineralization, etc.). In this way, the distribution of the labelled compound can be monitored through the different pools and be discriminated from the respective nutrient already present in the soil (for example, the ${ }^{15} \mathrm{~N}$ enriched fertilizer is distinguished by the native soil N) [8]. One limit of this approach is that the organic pool is considered as an undifferentiated whole; both $\mathrm{N}$ immobilization and $\mathrm{N}$ mineralization play a crucial role in affecting the amount of $\mathrm{N}$ available to plants, with the organic $\mathrm{N}$ pool being important in both processes with a part of it cycling more rapidly than the other part. [8]. Usually, models set up to simulate the $\mathrm{N}$ dynamics in soil represent both pools, but the advances in modeling $\mathrm{N}$ as well as $\mathrm{C}, \mathrm{P}$, and $\mathrm{S}$ in soil requires measurements of at least two organic pools with different biological activities.

Stable isotope probing (SIP) is a technique that combines the holistic approach with molecular methods because it can determine the active microbial population using the substrates labelled with stable isotopes (usually ${ }^{13} \mathrm{C}$ or ${ }^{15} \mathrm{~N}$ ); it directly links the function to the identification of species using the substrate because these species are present in heavy (labeled) DNA, which can be separated from light (unlabeled) DNA [12]. This technique can give insight not only into the stimulation of rare and dominant taxa using the labelled compound but also into the microbial taxa indirectly affected by the added compound by analyzing changes in the abundance of unlabeled taxa compared to those of the control soil (only water added) [40]. In addition, the determination of labelled phospholipid fatty acids (PLFA-SIP) can be used to trace the ${ }^{13} \mathrm{C}$-labelled compounds released by plants pulse-labelled with ${ }^{13} \mathrm{CO}_{2}$ not only into rhizosphere microorganisms but also into strictly plant-associated microorganisms [41]. There are two main drawbacks with the SIP technique: (i) the sensitivity of DNA-SIP is less than that of phospholipid fatty acid (PLFA)-SIP, because the former requires cell replication for incorporation and thus incubation times longer than those required for 
PLFA; and (ii) the cross-feeding —-that is, the labelling of microorganisms not directly involved in the substrate utilization but using the labelled metabolites produced by the users [12].

\section{Perspective}

Despite progression in the knowledge of the soil biological system promoted by both methodological advances and imaginative studies, many biological aspects of soil remain still obscure. Indeed, nowadays many issues about Waksman's questions are still poorly known despite more than 90 years of research. It is not possible to discuss here all these knowledge gaps due the vastness of the matter, involving the activity, abundance, and composition of soil organisms; interactions among them and with different plants; and the effects of different soil properties, environmental conditions, management practices, and polluting agents, etc. I shall only discuss one knowledge gap per each question as an example of the needed future research (Figure 1).

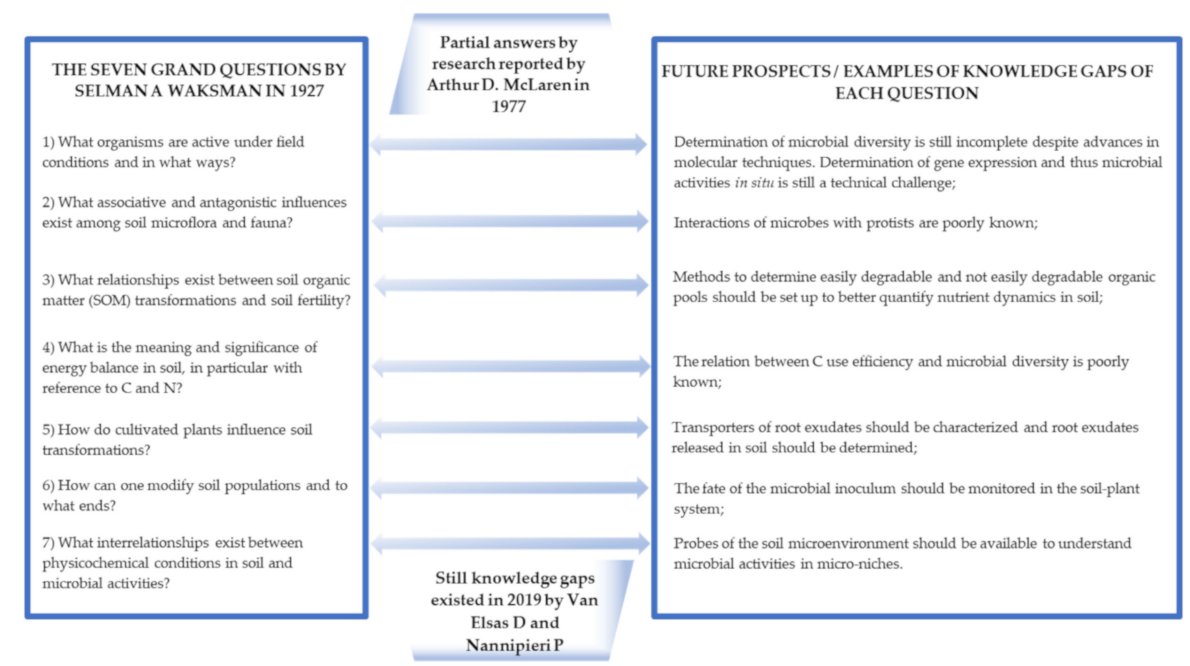

Figure 1. The seven grand questions by Selman A. Waksman and one knowledge gap for each question still present nowadays.

Concerning the first question, despite the use of molecular techniques, many species inhabiting soil are still undetected and future research should fill this gap. Several methods can determine microbial activity in soil, but the in situ determination of active microorganisms is questionable. The RNA/DNA ratio has been used as an indicator of microbial activity or microbial growth, as RNA synthesis is involved in activity and growth, whereas DNA increase is only involved in growth [42]. However, this ratio cannot be applied to clay soils, and its use does not discriminate maintenance-related synthesis versus microbial biomass production. The use of targeted transcriptomics/proteomics approaches is required but, as discussed above, soil proteomics especially are still a technical challenge.

The interactions between microorganisms and fauna are important (second question), as discussed above. However, there are several knowledge gaps about the interactions of microorganisms with all fauna components. Taking protists as an example of soil fauna, it is unknown which groups are the dominant ones in soil and, thus, which type of microbial interaction with protists is prevailing [29]

It is well established that soil organic matter plays a fundamental role in affecting soil fertility (third question). However, it is crucial to set up methods determining the easily degradable and the less degradable organic pool so as to trace main elements (C, N, P, and S) using the respective labelled compounds. This will improve the accuracy of models simulating the dynamics of these elements in soil. A great advance in soil nutrient studies was obtained by setting up the fumigation method, which enables the tracing of the dynamics of nutrients through soil microbial communities [43].

Soil microorganisms can use several organic substrates for energy provision or $\mathrm{C}$ supply, and this depends on several factors (fourth question), as discussed by Kästner and Miltner [44]. The $C$ use 
efficiency (CUE) (the ratio between the formed microbial biomass divided by the consumed substrate) can give insight into the amount of organic $C$ which potentially can accumulate in soil. According to Kästner and Miltner [44], it is crucial to have models predicting the organic C dynamics and energy balance in soil for the quantification of CUE and its relationship to soil microbial diversity.

It is still not possible to analyze root exudates in the presence of soil, despite their crucial role in the recruitment of microorganisms by plant roots (fifth question). Root exudates are collected under hydroponic conditions, but they differ in composition and properties when the plant is in the presence of soil. It is challenging to gain a complete extraction of root exudates from soil, not only because the extraction yield depends on the soil and exudate type but also because they are immediately used by microorganisms inhabiting the rhizosphere soil. Transporters involved in root exudation are mainly uncharacterized, and this knowledge is important in order to understand how and why plant roots release root exudates [26]. It is well established that distinct microbial communities colonize the several parts of the root due to spatially defined exudation, and the success of microbial colonization depends on chemotaxis, substrate specificity, competitiveness, and cooperativeness, but it is challenging to set up models considering all these issues.

The manipulation of the soil microbiome (sixth question) by inoculating specific microbial species in the soil-plant system for several purposes, such as controlling pathogens, improving plant growth, and bio-remediating polluted soils, has been extensively studied. However, the frequent failure of inoculated microorganisms depends on the fact that an insufficient number of inoculated active microbial cells carry out the function for which they have been inoculated in the soil-plant system. According to Gamalero and Glick [45], not only is the proper carrier of the inoculated microbial species important for the success of the inoculation, but so also is the proper understanding of the local conditions affecting the microbial inoculum. Finally, it is often a challenge to monitor the fate of the microbial inoculum in the soil-plant system, and this is crucial in order to understand the mechanisms of the effects of the inoculated microbial species [46].

Microbial activities in soil markedly depend on the soil physico-chemical properties, with temperature, moisture, and $\mathrm{pH}$ playing the most important role (seventh question). Several methods determine microbial activity in soil, but the most used is that determining carbon dioxide evolution from soil [8]. It is still challenging to understand how microorganisms perform their activities at the microenvironment scale. In 1982, Burns [23] concluded that it was not possible to verify experimentally the validity of his hypothesis on the ecological role of immobilized enzymes because of the lack of probes of the soil microenvironment. After almost 40 years, it is still challenging to simulate microenvironments under laboratory conditions.

\section{Conclusions}

This review has discussed briefly the main properties of soil as a biological system and the knowledge gaps that still persist for some of the questions raised in 1927 by Selman Waksman about the biological properties of soil. The persistence of these knowledge gaps is mainly due to the complexity of soil. Methodological progresses have allowed us to fill some of the knowledge gaps related to Waksman's questions. However, technology-driven research and hypothesis-driven research should be combined in order to fill the remaining gaps. Particularly imaginative research should address the simulation of the soil microenvironment so as to understand which factors regulate microbial activities in micro-niches. Of course, this is not an exhaustive review due to the complexity and vastness of the treated matter, which exceeds the limits of a single mini review; we suggest that the reader consult the many cited reviews to have a better view of the underlying mechanisms.

Funding: This research received no external funding.

Conflicts of Interest: The author declares no conflict of interest. 


\section{References}

1. McLaren, A.D. The seven questions of Selman A. Waksman. Soil Biol. Biochem. 1977, 9, 375-376. [CrossRef]

2. Van Elsas, J.D.; Nannipieri, P. The seven grand questions on soil microbiology (Selman A. Waksman, re-examined by Arthur D. McLaren). In Modern Soil Microbiology, 3rd ed.; Van Elsas, J.D., Trevors, J.T., Rosado, A.S., Nannipieri, P., Eds.; CRC Press: Baca Raton, CA, USA, 2019; pp. 21-35.

3. Oades, J.M.; Waters, A.G. Aggregate hierarchy in soils. Aust. J. Soil Res. 1991, 29, 815-828. [CrossRef]

4. Tisdall, J.M.; Oades, J.M. Organic matter and water-stable aggregates in soils. J. Soil Sci. 1982, 33, 141-163. [CrossRef]

5. Elliott, E.T.; Coleman, D.C. Let the soil work for us. Ecol. Bull. Natl. Speleol. Soc. 1988, 39, $23-32$.

6. Six, J. A history of research on the link between (micro) aggregates, soil biota, and soil organic matter. Soil Tillage Res. 2004, 79, 7-31. [CrossRef]

7. Coleman, D.C.; Crossley, D.A. Fundamentals of Soil Ecology; Academic Press: London, UK, 1996.

8. Nannipieri, P.; Ascher, J.; Ceccherini, M.T.; Landi, L.; Pietramellara, G.; Renella, G. Microbial diversity and soil functions. Eur J. Soil Sci. 2003, 54, 655-670. [CrossRef]

9. Dini-Andreote, F.; Van Elsas, J.D. The soil microbiome-An overview. In Modern Soil Microbiology, 3rd ed.; Van Elsas, J.D., Trevors, J.T., Rosado, A.S., Nannipieri, P., Eds.; CRC Press: Baca Raton, CA, USA, 2019; pp. 37-48.

10. Smith, J.L.; Paul, E.A. The significanceof soil microbial biomass estimations. In Soil Biochemistry; Bollag, J.-M., Stotzky, G., Eds.; Marcel Dekker: New York, NY, USA, 1990; Volume 6, pp. 357-396.

11. Delgado-Baquerizo, M.; Oliverio, A.M.; Brewer, T.; Benavent-Gonzalez, A.; Eldridge, D.J.; Bardgett, R.D.; Maestre, F.T.; Singh, B.K.; Fierer, N. A global atlas of the dominant bacteria found in soil. Science 2018, 359, 320-325. [CrossRef] [PubMed]

12. Nannipieri, P.; Ascher-Jenull, J.; Ceccherini, M.T.; Pietramellara, G.; Renella, G.; Schloter, M. Beyond microbial diversity for predicting soil functions: A mini review. Pedosphere 2020, 30, 5-17. [CrossRef]

13. Blagodatskaya, E.; Kuzyakov, Y. Active microorganisms in soil: Critical review of estimation criteria and approaches. Soil Biol. Biochem. 2013, 67, 192-211. [CrossRef]

14. Wei, X.; Hu, Y.; Razavi, B.S.; Zhou, J.; Shen, J.; Nannipieri, P.; Wu, J.; Ge, T. Rare taxa of alkaline phosphomonoesterase-harboring microorganisms meadiate soil phosphorus mineralization. Soil Biol. Biochem. 2019, 131, 62-70. [CrossRef]

15. Jiang, Y.; Song, H.; Lei, Y.; Korpelainen, H.; Li, C. Distinct co-occurrence patterns and driving forces of rare and abundant bacterial subcommunities following a glacial retreat in the eastern Tibetan Plateau. Biol. Fertil. Soils 2019, 55, 351-364. [CrossRef]

16. Lavelle, P.; Spain, A. Soil Ecology; Kluwer Academic Publisher: Dordrecht, The Netherlands, 2001.

17. Williamson, K.E.; Srinivasiah, S.; Wommack, K.E. Viruses in soil ecosystems. In Handbook of Soil Science: Perspectives and Processes; Huang, P.M., Li, Y., Summer, M.E., Eds.; CRC Press: Boca Raton, CA, USA, 2012; pp. 24.1-24.10.

18. Bernardo, P.C.M.; Charles-Dominique, T.; Barakat, M.; Ortet, P.; Fernandez, E.; Filloux, D.; Hartnady, P.; Rebelo, T.A.; Cousins, S.R.; Mesleard, F.; et al. Geometagenomics illuminates the impact of agriculture on the distribution and prevalence of plant viruses at the ecosystem level. ISME J. 2018, 12, 173-184. [CrossRef] [PubMed]

19. Juarez, S.; Nunan, N.; Duday, A.-N.; Pouteau, V.; Chenu, C. Soil carbon mineralisation responses to alterations of microbial diversity and soil structure. Biol. Fertil. Soils 2013, 49, 939-948. [CrossRef]

20. De Graaf, M.A.; Adkins, J.; Kardol, P.; Throop, H.L. A meta-analysis of soil biodiversity impacts on the carbon cycle. Soil 2015, 1, 257-271. [CrossRef]

21. Bao, Y.; Guo, Z.; Chen, R.; Wu, M.; Li, Z.; Lin, X.; Feng, Y. Functional community composition shows less environmental variability than 4 taxonomic composition in straw-degrading bacteria . Biol. Fertil. Soils 2020, 56. in press.

22. Singh, B.K.; Quince, C.; Macdonald, C.A.; Khachane, A.; Thomas, N.; Al-Soud, W.A.; Sorensen, S.J.; He, Z.; White, D.; Sinclair, A.; et al. Loss of microbial diversity in soils is coincident with reductions in some specialized functions. Environ. Microbiol. 2014, 16, 1-10. [CrossRef]

23. Burns, R.G. Enzyme activity in soil: Location and a possible role in microbial ecology. Soil Biol. Biochem. 1982, 14, 423-427. [CrossRef] 
24. Nannipieri, P.; Trasar-Cepeda, C.; Dick, R.P. Soil enzyme activity: A brief history and biochemistry as a basis for appropriate interpretations and meta-analysis. Biol. Fertil. Soils 2018, 54, 11-19. [CrossRef]

25. Pietramellara, G.; Ascher, J.; Borgogni, F.; Ceccherini, M.T.; Guerri, G.; Nannipieri, P. Extracellular DNA in soil and sediment: Fate nd ecological relevance. Biol. Fertil. Soils 2009, 45, 219-235. [CrossRef]

26. Sasse, J.; Martinoia, E.; Nothen, T. Feed your friends: Do plant exudates shape the root microbiome? Trends Plant. Sci. 2018, 23, 25-41. [CrossRef]

27. Van Elsas, J.D.; de Araujo, W.L.; Trevors, J.T. Microbial interactions. In Modern Soil Microbiology, 3rd ed.; Van Elsas, J.D., Trevors, J.T., Rosado, A.S., Nannipieri, P., Eds.; CRC Press: Baca Raton, CA, USA, 2019; pp. 141-161.

28. Bonkowsky, M.; Clarholm, M. Stimulation of plant growth through interactions of bacteria and protozoa: Testing the auxiliary microbial loop hypothesis. Acta Protozool. 2012, 51, 237-247.

29. Bonkowski, M.; Dumack, K.; Fiore-Donno, A.M. The protists in soil-A token of untold eukaryotc diversity. In Modern Soil Microbiology, 3rd ed.; Van Elsas, J.D., Trevors, J.T., Rosado, A.S., Nannipieri, P., Eds.; CRC Press: Baca Raton, CA, USA, 2019; pp. 125-140.

30. Samad, A.; Brader, G.; Pfaffenbichler, N.; Sessitsch, A. Plant-associated bacteria and the rhizosphere. In Modern Soil Microbiology, 3rd ed.; Van Elsas, J.D., Trevors, J.T., Rosado, A.S., Nannipieri, P., Eds.; CRC Press: Baca Raton, CA, USA, 2019; pp. 163-178.

31. Cooper, J.E. Early interactions between legumes and rhizobia: Disclosing complexity in a molecular dialogue. J. Appl. Microbiol. 2007, 103, 1355-1365. [CrossRef] [PubMed]

32. Martin, F.M.; Perotto, S.; Bonfante, P. Mycorrhizal fungi: A fungal community at the interface between soil and roots. In The Rhizosphere. Biochemistry and Organic Substances at the Soil-Plant Interface, 3rd ed.; Pinton, R., Varanini, Z., Nannipieri, P., Eds.; CRC Press: Boca Raton, CA, USA, 2007; pp. 201-236.

33. De Ridder-Duine, A.S.; Kowalchuk, G.A.; Gunnewiek, P.J.A.K.; Smant, W.; van Veen, J.A.; de Boer, W. Rhizosphere bacterial community composition in natural stands of Carex arenaria (sand sedge) is determined by bulk soil community composition. Soil Biol. Biochem. 2005, 37, 349-357. [CrossRef]

34. Yech, Y.K.; Dennis, P.G.; Paungfoo-Lohienne, C.; Weber, L.; Brackin, R.; Ragan, M.A.; Schmidt, S.; Hugenholtz, P. Evolutionary concervation of a core root microbiome across plant phyla along a tropical soil chronosequence. Nat. Commun. 2017, 8, 215-224.

35. Schlaeppi, K.; Dombrowski, N.; Oter, R.G.; van Thernaat, E.V.L.; Schulze-Lefert, P. Quantitative divergence of the bacterial root microbiota in Arabidopsis thaliana. Proc. Natl. Acad. Sci. USA 2014, 111, 585-592. [CrossRef] [PubMed]

36. Escudero-Martinez, C.; Bulgarelli, D. Tracing the evolutionary routes of plant-microbiota interactions. Curr. Opin. Microbiol. 2019, 49, 34-40. [CrossRef] [PubMed]

37. Fizpatrick, C.R.; Copeland, J.; Wang, P.W.; Guttman, D.S.; Kotanen, P.M.; Johnson, M.T.J. Assembly of ecological function of the root microbiome across angiosperm plant species. Proc. Natl. Acad. Sci. USA 2018, 115, E1157-E1165. [CrossRef]

38. Stozky, G. Influence of soil mineral colloids and metabolic processes, growth adhesion, and ecology of microbes and viruses. In Interactions of Soil Minerals with Natural Organics and Microbes; Huang, M., Schnitzer, M., Eds.; Soil Science Society of America: Madison, WI, USA, 1986; pp. 305-428.

39. Nannipieri, P.; Giagnoni, L.; Renella, G. Metaproteomics of soil microbial communities. In Modern Soil Microbiology, 3rd ed.; Van Elsas, J.D., Trevors, J.T., Rosado, A.S., Nannipieri, P., Eds.; CRC Press: Baca Raton, CA, USA, 2019; pp. 257-268.

40. Bao, Y.Y.; Dolfing, J.; Wang, B.Z.; Chen, R.R.; Huang, M.S.; Li, Z.P.; Lin, X.G.; Feng, Y.Z. Bacterial communities involved directly or indirectly in the anaerobic degradation of cellulose. Biol. Fertil. Soils 2019, 55, 201-211. [CrossRef]

41. Dias, A.C.F.; Dini-Andreote, F.; Hannula, S.E.; Dini-Andreote, F.; de Cassia Pereira e Silva, M.; Salles, J.F.; de Boer, W.; van Veen, J.; van Elsas, J.D. Different selective effects on rhizosphere bacteria exerted by genetically modified versus conventional potato lines. PLoS ONE 2013, 8, e67948. [CrossRef] [PubMed]

42. Loeppmann, S.; Semenov, M.; Kuzyakov, Y.; Blagodatskaya, E. Shift from dormancy to microbial growth revealed by RNA:DNA ratio. Soil Biol. Biochem. 2018, 85, 603-612. [CrossRef]

43. Jenkinson, D.S.; Powlson, D.S. The effect of biocidal treatments on metabolism in soil. V. A method for measuring soil biomass. Soil Biol. Biochem. 1976, 8, 209-213. [CrossRef] 
44. Kästner, M.; Miltner, A. SOM and microbes-What is left from microbial life. In The Future of Soil Carbon; Garcia, C., Nannipieri, P., Hernandez, T., Eds.; Academic Press: London, UK, 2018; pp. 125-163.

45. Gamalero, E.; Glick, B.R. Plant growth-promoting rhizobacteria in agricultural and stressed soil. In Modern Soil Microbiology, 3rd ed.; Van Elsas, J.D., Trevors, J.T., Rosado, A.S., Nannipieri, P., Eds.; CRC Press: Baca Raton, CA, USA, 2019; pp. 361-380.

46. Rilling, J.I.; Acuna, J.J.; Nannipieri, P.; Cassan, F.; Maruyama, F.; Jorquera, M.A. Current opinion and perspectives on the methods for trackimg and monitoring plant growth-promoting bacteria. Soil Biol. Biochem. 2018, 130, 205-219. [CrossRef]

(C) 2020 by the author. Licensee MDPI, Basel, Switzerland. This article is an open access article distributed under the terms and conditions of the Creative Commons Attribution (CC BY) license (http://creativecommons.org/licenses/by/4.0/). 